\title{
Modeling of the structure and properties of a mineral wool cylinders
}

\author{
Kazbek Ivanov $^{1, *}$, and Boris Efimov ${ }^{1}$ \\ ${ }^{1}$ Moscow State University of Civil Engineering (NRU MGSU), 129337 Moscow 26 Yaroslavskoye \\ Sh., Russia
}

\begin{abstract}
Thermal insulation is used in almost all industries, providing technological requirements, operational reliability and trouble-free operation of facilities, many of which are classified as explosive and fire hazardous or pose a danger to human health and the environment. Mineral wool cylinders are used to insulation of pipelines in all industries. The main segment is pipeline insulation in various industries for a pipe with small diameter of 12 to $273 \mathrm{~mm}$. When insulating pipes of a larger diameter, segments (half-cylinders) or mats are used. It is widely used at all facilities without restriction, such as: multifunctional shopping centers, private housing, apartment buildings, factories and pipelines of technical equipment, food industry (at the food industry plants apply high fire safety requirements, as well as cleanliness in the workspace), hospitals, kindergartens, schools.
\end{abstract}

\section{Introduction}

Thermal insulation of industrial structures, equipment and pipelines in the heat power industry: boilers, steam and gas turbines, high chimneys 190-350 m high, tanks for storing liquid fuel, liquefied natural and hydrocarbon gases, gas holders, heating networks, etc. ; in the industry of construction materials, chemical industry, oil and gas processing, metallurgy, food and other branches of industrial production: furnaces, dryers, column-type apparatuses, refrigerators, etc. - it received the collective name of industrial insulation [1-3]. A distinctive feature of industrial thermal insulation is the wide temperature range of the insulated surfaces - from minus 180 to $600^{\circ} \mathrm{C}$ - and a high level of heat flow through them, which is 10-15 times higher than the level of heat flow through thermal insulation of residential, public and industrial buildings. The vast majority (85-90\%) of industrial thermal insulation is mounted from fibrous materials (mineral wool and fiberglass products). At the same time, more than $55 \%$ of insulation works at facilities with a thermal insulation temperature of up to $200^{\circ} \mathrm{C}$, about $25 \%$ in the temperature range of $180-400{ }^{\circ} \mathrm{C}, 5 \%$ in the range of $401-600^{\circ} \mathrm{C}$, and only $0.1 \%$ of thermal insulation is mounted from inorganic molded products at objects with a temperature above $600{ }^{\circ} \mathrm{C}$ [4-6], and $15 \%$ at a negative temperature from minus $14^{\circ} \mathrm{C}$ to minus $180^{\circ} \mathrm{C}$.

\footnotetext{
*Corresponding author: petrel@bk.ru
} 
The main heat-insulating layer is designed to reduce the rate of heat flow. The protectivesheathing ensures the safety of the heat-insulating layer in operating conditions, protecting it from external factors - precipitation, pulsating wind loads and other influences. The vapor barrier layer is used to prevent humidification of the thermal barrier layer due to condensation of moisture from the air. Fasteners (bandages, pins, couplers, screws, etc.) provide reliable fixation of the structure in the design position $[7,8]$.

\section{Results}

To evaluate the effectiveness of industrial thermal insulation, we used the normative indicators of heat losses developed by the "Teploproekt" Institute; data on the length of technological pipelines in various industries, a matrix of the distribution of the lengths of insulated technological pipelines by diameters and sizes, and the results of studies on reducing the thermal resistance properties of industrial thermal insulation during operation.

During the development of the calculation method for determining the effective thermal conductivity of fibrous materials, the model of O. Krisher was used to determine its conductive component $[9,10]$. The model gives quite satisfactory results when calculating the thermal conductivity of heat-insulating materials, which are widely used in industrial insulation designs.

The calculation formulas of this model for determining the conductive thermal conductivity of materials in a dry state are:

$$
\begin{aligned}
& \lambda_{q}=\frac{1}{(1-a) / \lambda_{1}+a / \lambda_{2}} ; \\
& \lambda_{1}=(1-m) \lambda_{f}+m \lambda_{g} ; \\
& \lambda_{2}=\frac{1}{(1-m) / \lambda_{f}+m / \lambda_{g}} ;
\end{aligned}
$$

$a$ is the experimentally determined coefficient characterizing the structure of the material; $m$ is the porosity of the material in percent; $\lambda_{f}$ - thermal conductivity of the fiber; $\lambda_{g}$ - thermal conductivity of the gas filling the porous structure of the material.

The considered model also allows us to determine the conductive part of thermal conductivity of the moistened layer of the structure:

$$
\begin{aligned}
& \lambda_{q}^{w}=\frac{1}{(1-a) / \lambda_{1}^{w}+a / \lambda_{2}^{w}} ; \\
& \lambda_{1}^{w}=(1-m) \lambda_{f}+W \cdot \lambda_{h}+(m-W) \lambda_{g} ; \\
& \lambda_{2}^{w}=\frac{1}{(1-m) / \lambda_{f}+W / \lambda_{g}+(m-W) \lambda_{g}} ;
\end{aligned}
$$

$\lambda_{h}$ - the thermal conductivity of water, $W$ - the effective moisture content in the material, related to the relative moisture content of the material $U$ in $\mathrm{kg}$ of moisture per $\mathrm{kg}$ of dry weight of material by the ratio: $W=U \cdot \gamma / \rho_{h}$ where $\rho_{h}$ is the density of water, $\gamma$ is the average density of the material. 
Table 1. Thermal conductivity, fiber density and structural characteristics of fibrous materials

\begin{tabular}{|c|c|c|c|}
\hline Mineral fiber & Mullite - silica fiber & Basalt fiber & Glass fiber \\
\hline \multicolumn{2}{|c|}{$\lambda_{f}=1,2+8,5 \cdot 10^{-5}\left(t_{m}+100\right)$} & $\lambda_{f}=1,23+8,6 \cdot 10^{-5}\left(t_{m}+100\right)$ \\
\hline$a=0,69$ & $a=0,70$ & $a=0,70$ & $a=0,76$ \\
\hline$\rho_{f}=1000$ & $\rho_{f}=1700$ & $\rho_{f}=1700$ & $\rho_{f}=1000$ \\
\hline
\end{tabular}

To evaluate the thermal conductivity of fibrous insulation can be used table. 1, which shows the calculated values of the effective thermal conductivity depending on the temperature of the insulated surface, bulk density and fiber diameter at an ambient temperature of $20^{\circ} \mathrm{C}$.

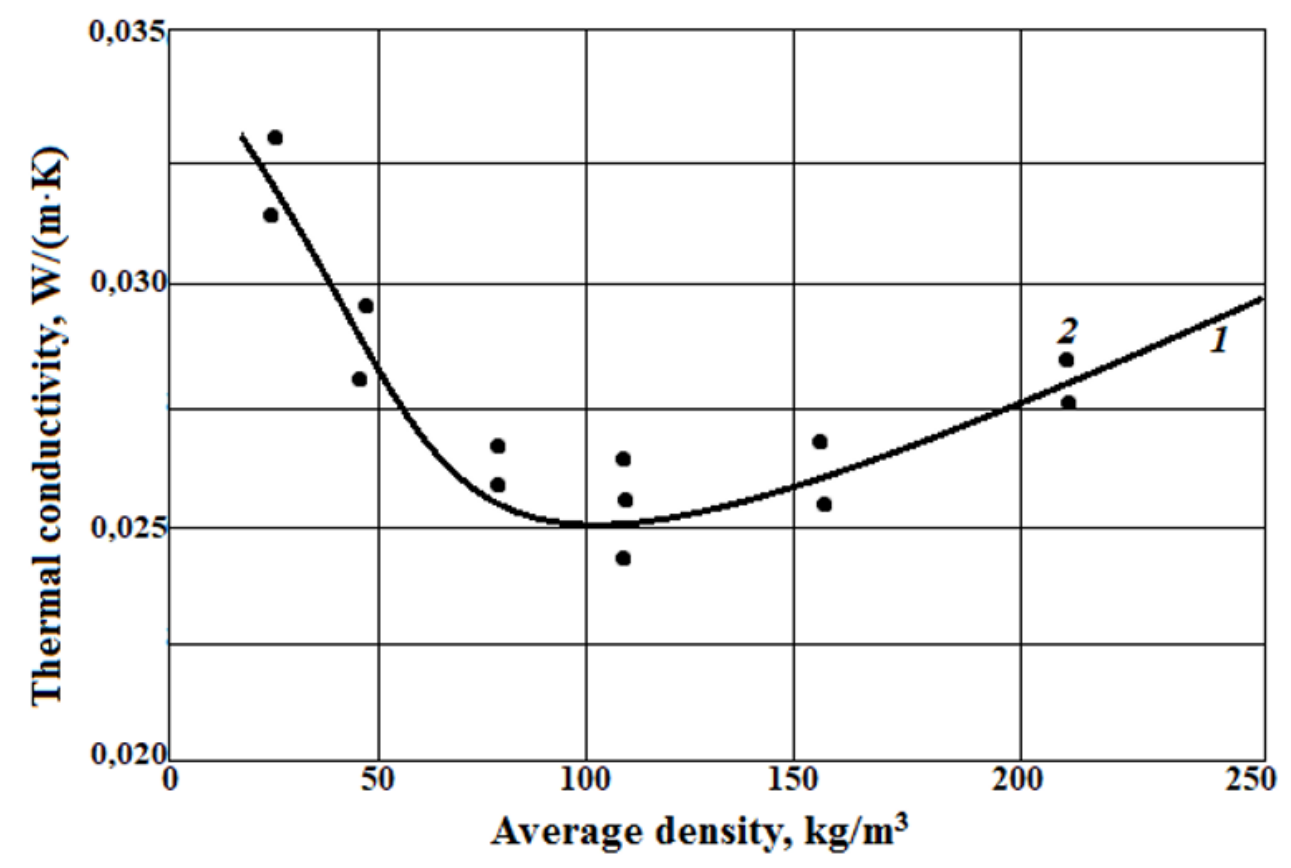

Fig. 1. Relation between thermal conductivity of a cylindrical fiber insulation sample made of basalt fiber with an average diameter of $3 \times 10^{-6} \mathrm{~m}$ and density at $d_{p}=100 \mathrm{~mm}, t_{p}=180^{\circ} \mathrm{C}, d_{T}=20 \mathrm{Mm}, t_{T}=$ $20^{\circ} \mathrm{C}: 1$ - experimental data; 2 - calculation results. 


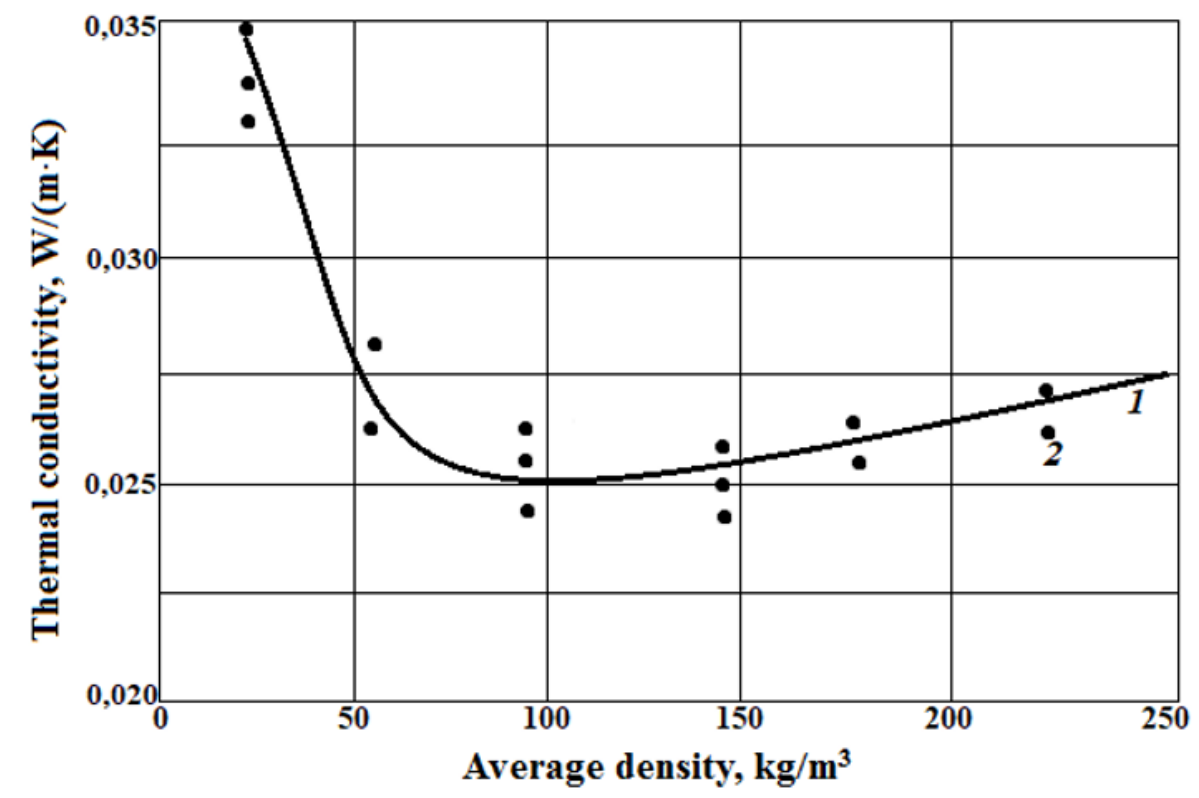

Fig. 2. The relation between thermal conductivity of a cylindrical fiber insulation sample made of basalt fiber with an average diameter of $7 \times 10^{-6} \mathrm{~m}$ and density at $d_{p}=100 \mathrm{~mm}, t_{p}=180^{\circ} \mathrm{C}, d_{T}=20$ мм, $t_{T}=20^{\circ} \mathrm{C}: 1$ - experimental data; 2 - calculation results.

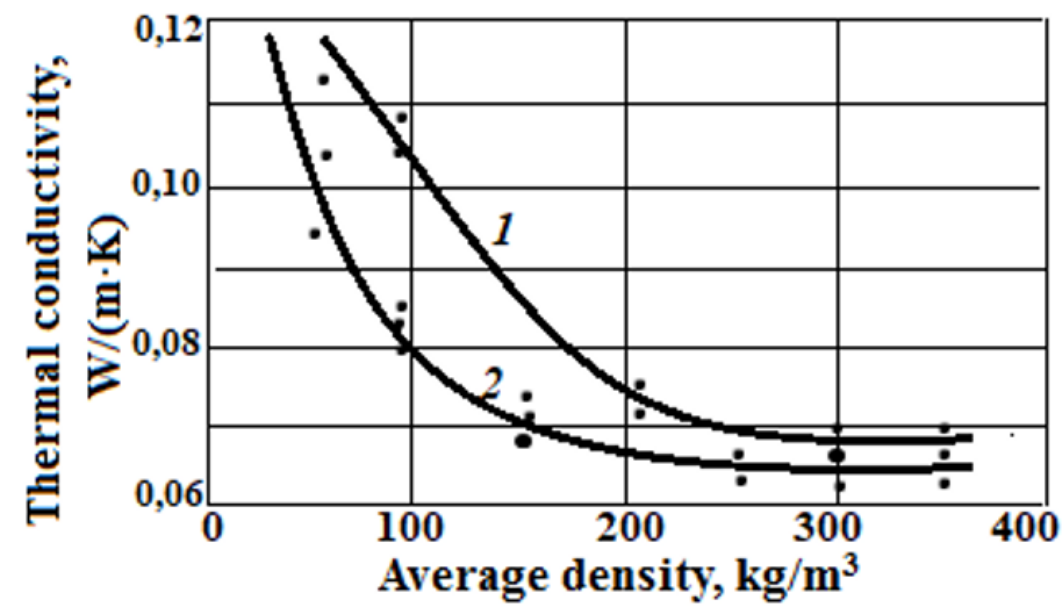

Fig. 3. The relation between of the thermal conductivity of a cylindrical sample of basalt fiber insulation with an average diameter of $3 \times 10^{-6} \mathrm{~m}(1)$ and $7 \times 10^{-6} \mathrm{~m} \mathrm{(2)}$ and the density at $d_{p}=100 \mathrm{~mm}$, $t_{p}=500^{\circ} \mathrm{C}, d_{T}=18 \mathrm{~mm}$. 


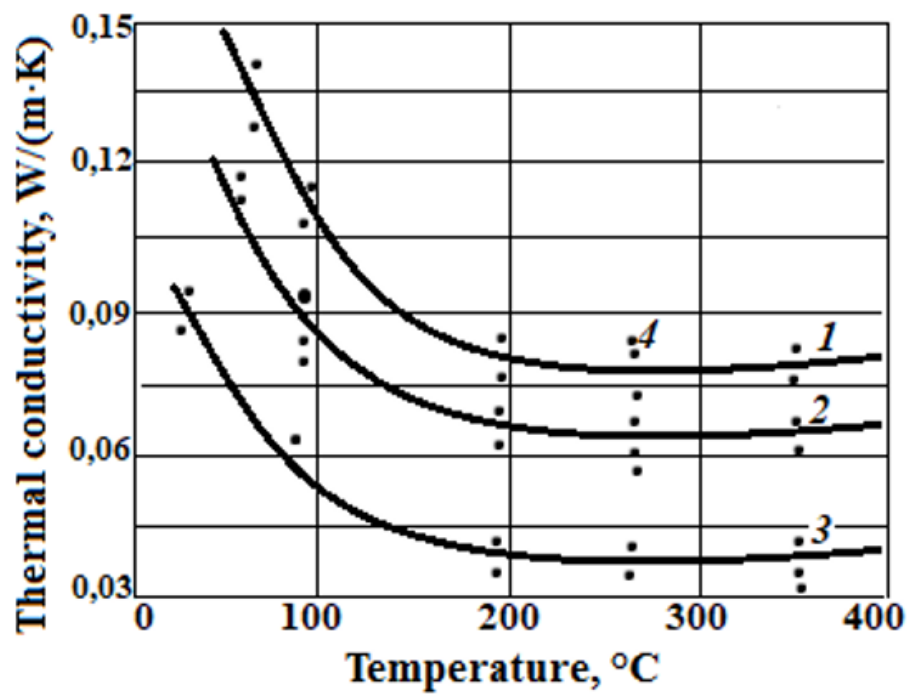

Fig. 4. The relation between the effective thermal conductivity of mineral wool $d_{f}=7 \times 10^{-6} \mathrm{~m}$ and the average density at a temperature of: $1-300{ }^{\circ} \mathrm{C} ; 2-200{ }^{\circ} \mathrm{C} ; 3-25^{\circ} \mathrm{C}$ - calculated curves; 4 - experimental data

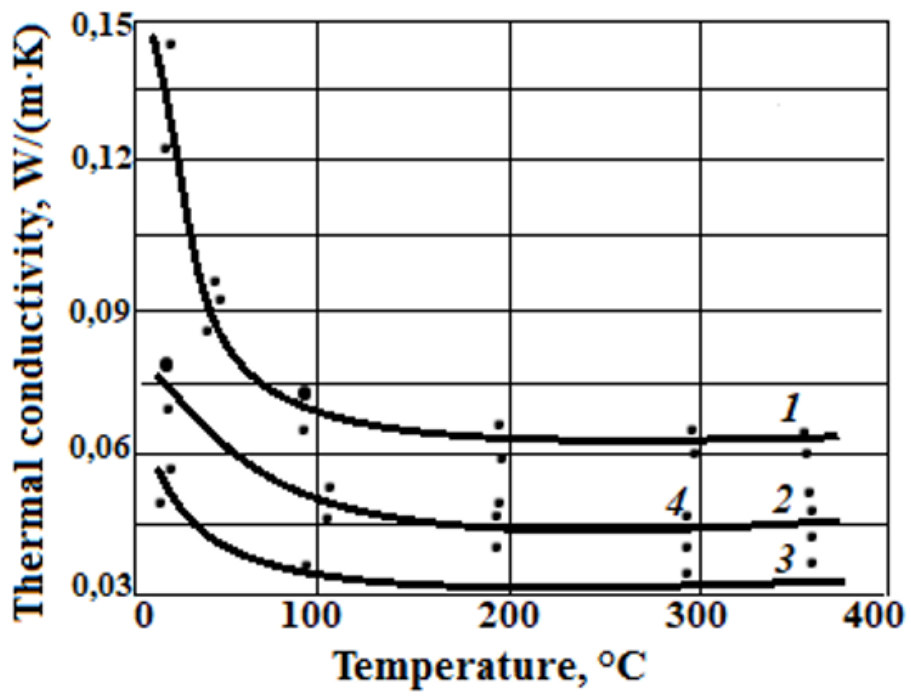

Fig. 5. The relation between the effective thermal conductivity of mineral wool $d_{f}=2 \times 10^{-6} \mathrm{~m}$ and the average density at a temperature of: $1-300^{\circ} \mathrm{C} ; 2-200^{\circ} \mathrm{C} ; 3-25^{\circ} \mathrm{C}$ - calculated curves; 4 - experimental data

An analysis of the results of experimental studies of the thermal resistance properties of fibrous materials in cylindrical structures (Fig. 1, 2,3) and the calculated data obtained for the conditions of the experiments using the model of effective thermal conductivity of fibrous materials $(1,2)$ showed their good quality and quantitative convergence. To confirm the adequacy of the developed model of the mechanism of heat and mass transfer and its suitability for determining the effective thermal conductivity of fibrous materials, we also used experimental data on the effect of temperature on heat-insulating materials obtained by various authors using the stationary mode method on flat samples. 


\section{Discussion}

Summarizing the results of experimental data on the thermal conductivity of fibrous materials in cylindrical structures obtained under bench conditions, experimental data obtained by various authors on the basis of laboratory tests of flat samples by the stationary mode method [10-13] and the results of numerical simulations of the effective thermal conductivity of fibrous materials, we managed to determine:

- the relation between the effective thermal conductivity and the density of thermal insulation at negative and high temperatures has the same nature for all examined fibrous materials and is described by a smooth curve with a minimum, the maximum value of the effective thermal conductivity coefficient acquires at a low density of the material and then decreases with increasing density, reaching at a certain density minimum, and then, with its increase, also increases thermal conductivity coefficient;

- the value of the density of the material at which the thermal conductivity reaches a minimum value increases with increasing temperature of the insulated surface;

- the type of fiber has an insignificant effect on the effective thermal conductivity of the examined fibrous materials, while the minimum thermal conductivity of the examined materials has fiberglass, the maximum has a mineral fiber;

- with increasing of a fiber diameter, the effective thermal conductivity of the fibrous insulation increases, and the effect of the fiber diameter on the thermal conductivity depends on the density of the material;

- upon transition from thin fibers $(1.5-3 \mu \mathrm{m})$ to thick $(9-12 \mu \mathrm{m})$, the thermal conductivity of low-density insulation (30-40 kg / m3) increases by 2-3 times, in the range of optimal densities $(75-150 \mathrm{~kg} / \mathrm{m} 3)$ its increase by $1.3-1.4$ times, and at a density exceeding $250 \mathrm{~kg} /$ $\mathrm{m} 3$, it practically does not depend on the fiber diameter;

- the geometric parameters of heat-insulating structures have an insignificant effect on effective thermal conductivity only at a low insulation density $(20-40 \mathrm{~kg} / \mathrm{m} 3)$ and only in the range of negative temperatures of the insulated surface: minus $100^{\circ} \mathrm{C}$ and below;

- the intensity of heat transfer by radiation in fibrous materials increases with temperature, and at temperatures of $150^{\circ} \mathrm{C}$ and higher it has the same order as the intensity of conductive transfer, with increasing of a fiber diameter radiation thermal conductivity increases, and with increasing insulation density it decreases;

- with all other conditions being equal, the radiation thermal conductivity of fiberglass is almost 2 times lower than the radiation thermal conductivity of mineral and basalt fiber, the radiation thermal conductivity of which is approximately the same;

- the convective component of effective thermal conductivity has a significant role: at negative temperatures of the insulated surface, low insulation density and large fiber diameters;

- the convective component of effective thermal conductivity has an insignificant effect at positive temperatures.

In addition to the introduction of new progressive norms of heat energy loss, increasing stability of the thermal resistance properties of industrial insulation during operation is of great importance for saving fuel and energy resources.

A decrease in the thermal resistance properties of the heat-insulating structures of industrial structures, equipment and heat pipes with a positive temperature based on fiber insulation (at least $85-90 \%$ of all industrial insulation) occurs due to the following reasons.

During operation, due to variable thermal effects, mechanical stresses caused by vibration of the equipment and wind pressure in a variable direction, as well as due to wetting and drying during periodic shutdown of the equipment, the heat-insulating fiber layer is compacted, the insulation thickness decreases, its thermal conductivity increases. The heatinsulating structure changes its shape ("sags"), air cavities with enhanced air convection are 
forming inside it, which leads to a decrease in the overall thermal resistance of the heatinsulating layer. The tightness of the coating layer is impaired and, as a result, occurs a circulation between the internal cavity of the heat-insulating structure and the environment and also moistening of the fibrous layer, which increases heat loss. According to the results of inspections of industrial facilities, including thermal imaging, due to these reasons, losses, compared with normative, increase by $20-30 \%$.

\section{Conclusions}

Industrial thermal insulation is an important element in the design of insulated structures and equipment, because, as a rule, it fulfills not only its traditional role - reducing heat energy losses to the environment, but also, in most cases, ensures compliance with the required thermal regimes of equipment and the technological regime implemented by it. Therefore, the effectiveness of industrial thermal insulation is determined not only by its high heatinsulating properties, but also by the stability of the thermal resistance properties of heatinsulating structures during operation. The choice of a technical solution for thermal insulation should be made taking into account the structural features of the object, its orientation in space, external atmospheric influences and, of course, the intended purpose of thermal insulation.

The manufacturability of structures during manufacturing and installation is especially important, since its absence can cause poor-quality installation of insulation and, as a consequence, its premature destruction.

\section{References}

1. P.M. Zhuk, A.D. Zhukov, Normative legal base for the environmental assessment of building materials: prospects for improvement, Ecology and industry of Russia, № 4, pp. 52-57 (2018)

2. B.M. Rumyancev, A.D. Zhukov, T.V. Smirnova, Thermal conductivity of highly porous materials, Vestnik MGSU, № 3, pp. 108-114 (2012)

3. A.D. Zhukov, E.Yu. Bobrova, D.B. Zelenshchikov, R.M. Mustafaev, A.O. Khimich, Insulation systems and green sustainable construction, Advanced Materials, Structures and Mechanical Engineering, v. 1025-1026, pp. 1031-1034 (2014)

4. I.V. Bessonov, A.V. Starostin, V.M. Oskina, About shape stability of the fibrous insulation, Vestnik MGSU, № 3, pp. 134-139 (2011)

5. D. Tuchaev, E. Zarmanyan, E. Petrovskiy, A. Zemlyanko, K. Ivanov and A. Zhukov. Thermal insulation systems for the Arctic. FORM 2018. IOP Conf. Series: Materials Science and Engineering, doi:10.1088/1757-899X/365/3/032015032041 (2018)

6. B.M. Shoyhet, L.V. Stavritskaya, Ya. A. Kovylianskii, Thermal insulation of pipelines of heating networks. Modern materials and technical solutions, "Yenergosberezheniye", № 5, pp. 43-45 (2002)

7. B.M. Rumyancev, A.D. Zhukov, Basalt fiber and woven materials based on it, “I.V.T.T.P”, №. 3, pp. 114-116 (2017)

8. A.D. Zhukov, I.V. Bessonov, A.N. Sapelin, R.M. Mustafaev, Composite materials with adjustable porosity, "PGS”, № 6, pp. 58-61 (2014)

9. N.P. Umnyakova, V.M. Tsygankov, V.A. Kuzmin, Experimental thermal engineering research for the rational design of wall structures with reflective thermal insulation, “Zhilishchnoe stroitel'stvo", № 1-2, pp. 38-42 (2018) 
10. B.M. Rumiantcev, A.D. Zhukov., E.Yu. Bobrova, I. P. Romanova, D.B. Zelenshikov, T.V. Smirnova, The systems of insulation and a methodology for assessing the durability, MATEC Web of Conferences. v. 86, DOI: http://dx.doi.org/10.1051/matecconf/ 20168604036 (2016)

11. B.M. Rumiantcev, A.D. Zhukov, D.B. Zelenshikov, A.S. Chkunin, K.K. Ivanov, Yu.V. Sazonova, Insulation systems of the building construtions, MATEC Web of Conferences. v. 86, DOI: http://dx.doi.org/10.1051/matecconf/ 20168604027 (2016)

12. I.Ya. Gnip, S.I. Vaitkus, Analytical description of mineral wool creeping deformation during prolonged compression, Building materials, № 11, pp. 57-62 (2013)

13. A.D. Zhukov, K.K. Ivanov, D.I. Aristov, E.R. Pyataev, Optimization of heat treatment of mineral wool cylinders, "Privolzhskiy NZH” № 3, pp. 76-82 (2015) 